Article

\title{
Improvement of Battery Life and Energy Economy for Electric Vehicles with Two-Speed Transmission
}

\author{
Ying Lyu ${ }^{1,2}$, Xuenan Sun ${ }^{3}$, Hong Chu ${ }^{1}$ and Bingzhao Gao ${ }^{1, *}$ \\ 1 State Key Laboratory of Automotive Simulation and Control, College of Automotive Engineering, \\ Jilin University, Changchun 130025, China; lvying@faw.com.cn (Y.L.); zhuhong17@mails.jlu.edu.cn (H.C.) \\ 2 State Key Laboratory of Comprehensive Technology on Automobile Vibration and Noise \& Safety Control, \\ Changchun 130000, China \\ 3 School of Mathematics and Statistics, Northeast Normal University, Changchun 130024, China; \\ sunxn107@nenu.edu.cn \\ * Correspondence: gaobz@jlu.edu.cn; Tel.: +86-431-85095198
}

Received: 13 June 2020; Accepted: 30 June 2020; Published: 2 July 2020

\begin{abstract}
With the current energy environment background and development of the electrification of the automotive industry, a comprehensive economic indicator, in which the battery aging is further considered on the basis of conventional energy consumption, is proposed to research the energy optimization problem of two-speed electric vehicles. Firstly, a battery life model that adapts to vehicles under high dynamic conditions is introduced. Then, the speed optimal control problem of the two-speed electric vehicles in the acceleration-cruise-deceleration process is established and solved. Finally, the simulation results of two different performance indicators are contrasted and the performance improvement of the two-speed gearbox to the electric vehicles is analyzed. The simulation results under various working scenarios and driving cycles demonstrate that, compared with the conventional economic indicator considering the energy consumption only, the proposed economic indicator can significantly improve the battery life. In addition, it can also be seen that, compared with the one-speed electric vehicles, the application of a two-speed gearbox provides better performance from the aspects of battery aging saving and energy consumption.
\end{abstract}

Keywords: two-speed electric vehicles; battery aging model; economic indicators; travel speed planning; sequence quadratic programming

\section{Introduction}

Against the background of the depletion of petroleum resources and the deterioration of the global security environment for petroleum supplies [1], the automotive industry's oil consumption has reached $30 \%$ of total domestic oil consumption in China, which has caused enormous energy pressure. At the same time, such a huge oil consumption in the automobile industry has also brought serious environmental pollution problems, such as carbon dioxide emissions, nitrogen oxide emissions, and so on, and the urgency of pollution prevention and control has become increasingly prominent [2]. In order to reduce the energy consumption of the automobile industry and solve the increasingly serious pollution of automobile emissions, new energy vehicles, such as electric vehicles, have become the development direction of automobiles in the future, and have received the attention and policy support of various countries [3].

As one of the core components of pure electric vehicles, the power battery directly determines the performance of electric vehicles. Compared with other types of power batteries, lithium batteries have relatively high energy density, about 3-4 times that of Ni-Cd batteries, as well as a long service life and low self-discharge rate [4-6]. Therefore, lithium-ion batteries have become the preferred energy 
storage device for electric vehicles. However, the current energy density of lithium-ion battery for vehicles still cannot support the long-distance driving of electric vehicles [7]. In the context of battery technology that cannot be achieved in a short period of time, some technologies for electric vehicle energy management, such as real-time control [8], predictive cruise control [9], adaptive intelligent energy management systems [10], brake energy recovery [11,12], supercapacitors [13], and longitudinal speed optimization [14], have been used. For example, by applying speed optimization technology during the driving of electric vehicles, the service life of the power battery is improved, thereby reducing the use cost of the electric vehicle user and improving the economy.

In recent years, intelligent transportation systems have received widespread attention [15]. Under the intelligent transportation system, vehicles can communicate with the traffic signal system, so that the vehicle density of each road is lower than a threshold as much as possible, so as to improve traffic efficiency and alleviate road congestion, thereby achieving energy saving and emission reduction purposes [16]. Vehicle longitudinal speed optimization is an important part of intelligent driving technology [17]. On the basis of information communication and control technology, speed optimization enables the vehicle to have the speed control function adapting to the working condition and target, which has great application potential. With the popularity of electric vehicles, the short service life of lithium-ion batteries has been a bottleneck of electric vehicles' development, and it is also one of the problems that must be solved in the field of electric vehicles. In addition, the price of lithium-ion batteries is high, occupying a significant share of the cost of electric vehicles. If an additional replacement of the power battery is required during the service life of an electric vehicle, the cost of using electric vehicles will be greatly increased. In particular, for electric vehicles, in order to avoid premature aging of the battery and increase the use time of the battery, the economic index should include not only the energy consumption cost, but also the aging cost of the power battery. Therefore, the energy consumption cost and aging cost of power battery will be considered comprehensively in the performance index of speed optimization in this paper.

Along with the use of electric vehicles, many aging processes inevitably occur in power batteries $[18,19]$. Battery aging is mainly determined by factors such as temperature, charge-discharge rate $\left(c_{\text {rate }}\right)$ cycle numbers, and depth of discharge (DOD), and a battery life model is established based on these factors [20-22]. However, most of the modeling information comes from test results in a highly-controlled laboratory environment, and such battery aging models may not accurately reflect the aging of the vehicle's power battery $[17,23]$. As the battery experiences an irregular charging and discharging process under actual driving conditions, accurately estimating battery life is a huge challenge. This paper will propose a control-oriented quantified battery life model that adapts to the vehicle even in the highly dynamic driving conditions and its specific details will be put forward in the following sections.

Although single-gear transmission is widely used in electric vehicles, the role of two-gear transmission in improving the performance of electric vehicles is attracting widespread attention and trial application from relevant research teams and electric vehicle manufacturers. For pure electric vehicles, the wide range of speed regulation of the motor determines that direct drive or matching the transmission with two gears can meet the requirements of power and economy. Therefore, related research is mainly focused on the two-speed gearbox. A comparative study of pure electric vehicles with fixed speed ratio reducers and two gearboxes was carried out at the University of Sunderland, UK [24]. The results show that the two-speed gearbox can effectively improve the motor efficiency and decrease the size and quality of the power transmission system. The Darmstadt University of Technology in Germany proved that the power performance of pure electric vehicles equipped with two-speed gearboxes has been significantly improved [25]. Aldo Sorniotti of Italy conducted some research on the two-speed gearbox, and analyzed the effect of the two-speed transmission and the single-gear transmission on the economy of pure electric vehicles [26]. The simulation results and real vehicle experiments show that the two-speed gearbox assembly of pure electric vehicle is better than the single-speed gearbox in economy and power. At the same time, based on the gearbox's research on 
shift control, the gearbox can realize unpowered interrupt shifting and improve the power performance of pure electric vehicles [27].

In order to illustrate the importance of introducing battery life into economic indicators and the role of two-speed gearboxes in improving the economics of electric vehicles, this paper discusses the energy optimization problem of two-speed electric vehicles and supplements the economic indicators of the electric vehicles, that is, comprehensively considers the energy consumption and life of the battery and does not focus on the battery energy consumption only. In addition, in order to quantify the aging of the battery, a battery life model adapted to the vehicle under high dynamic conditions is put forward.

The remainder of the paper is arranged as follows. In Section 2, a control-oriented battery life model that can be used in actual driving conditions is proposed. In Section 3, the optimization problem of the economical travel speed is established with four aspects. Section 4 describes the solving algorithm of the speed optimization problem. The simulation results of different performance indicators and transmission are compared and analyzed and the simulation is verified under the New European Driving Cycle (NEDC) and Urban Dynamometer Driving Schedule (UDDS) cycle conditions in Section 5. In the end, conclusions are provided in Section 6.

\section{Battery Life Estimation Model}

Depending on the battery performance properties being studied, that is, capacity fade or internal resistance increase; battery life type, that is, calendar or cycle life; and different modeling methods, models for estimating battery life are of different types and can generally be divided into electrochemical models [28], empirical models [29], and semi-empirical models [30]. The electrochemical model theoretically explains the actual electrochemical reactions leading to battery aging and predicts the battery life based on this. On the basis of a great deal of experimental data, the mathematical relationship between battery aging and some factors is established, and the empirical model uses this empirical method to establish the battery life model. However, both electrochemical models and empirical models have their drawbacks. Electrochemical models are very complex and theoretical, which makes it difficult to achieve practical engineering applications. Empirical models require a large amount of experimental data and are only applicable under specific experimental conditions. The semi-empirical model combines the theoretical principle of the electrochemical model with the experimental results of the empirical model to obtain the fitting parameters of the model, which combines the advantages of the two methods. Therefore, the semi-empirical model is simpler than the electrochemical model and has wider application conditions than the empirical model.

The aging of batteries in use will affect the performance of batteries. The battery performance degradation is shown by the increase of internal resistance and the decline of battery capacity, which will lead to the reduction of specific energy and specific power of batteries, respectively. According to the previous analysis, the mechanisms of battery aging are complicated. Through long-term experiments and extensive research on various batteries, battery aging depends on various factors, mainly including working temperature, battery charge-discharge rate, cycle numbers, and depth of discharge. However, most of the available information about battery aging is based on the results of cycle life experiments obtained under specific experimental conditions, which can not accurately reflect the high dynamic conditions experienced by the battery in the actual driving process of the vehicle. Therefore, when the battery aging model derived from this kind of experimental data is used to estimate battery life, there may be a big difference between the actual battery aging data and the aging data obtained from the model, which will lead to conservative vehicle design by the electric vehicle manufacturers. For example, battery systems usually have excess performance to ensure the driving range of the electric vehicle, while also increasing the cost of the battery system. In order to accurately estimate the battery life under actual operating conditions, this article refers to a mathematical battery life model for the control-oriented quantifiable battery life [14]. 
According to the main factors that affect the decline of battery capacity, a semi-empirical battery life model can be shown as [22]

$$
Q_{\text {loss }}(t)=B e^{\left(\frac{-31700+370.3 c_{\text {rate }}}{R T}\right)}(A h(t))^{z}
$$

where $Q_{\text {loss }}(t)$ is the rate of battery capacity loss, $B$ is the pre-exponential factor increasing with the $c_{\text {rate, }} R$ is the universal gas constant, $T$ is the absolute temperature, $z$ is the power law factor, and $A h$ is the total Ah-throughput:

$$
A h(t)=\int_{0}^{t}|i(\tau)| d \tau
$$

The $c_{\text {rate }}$ is the ratio of the current $i$ (in $A$ ) to the nominal charge capacity $S_{0}$ (in $A h$ ):

$$
c_{\text {rate }}=\frac{i}{S_{0}}
$$

The above battery life model is suitable for calculating the lithium-ion battery capacity loss under fixed cycle conditions. In order to accurately estimate the battery life for changing charge/discharge current, temperature, and other factors under actual operating conditions, a mathematical model for the control-oriented quantifiable battery life is presented here according to work of [14]. In electric vehicles, the battery is considered to have run out of life when it reaches $80 \%$ of its original capacity. According to the reference, some assumptions are given to derive the formula and the variation tendency of a battery capacity loss during actual operating conditions is given as shown in Figure 1 . The equivalent variable Ah-throughput $\overline{A h}(t)$, which equals the battery capacity loss $Q_{\text {loss }}(t)$ under a fixed condition (constant charge/discharge current and constant temperature) at time $t$, is obtained as

$$
\overline{A_{h}}(t)=\frac{Q_{\text {loss }}^{2}(t)}{M_{1}^{2} e^{2 M_{2} i(t)}}
$$

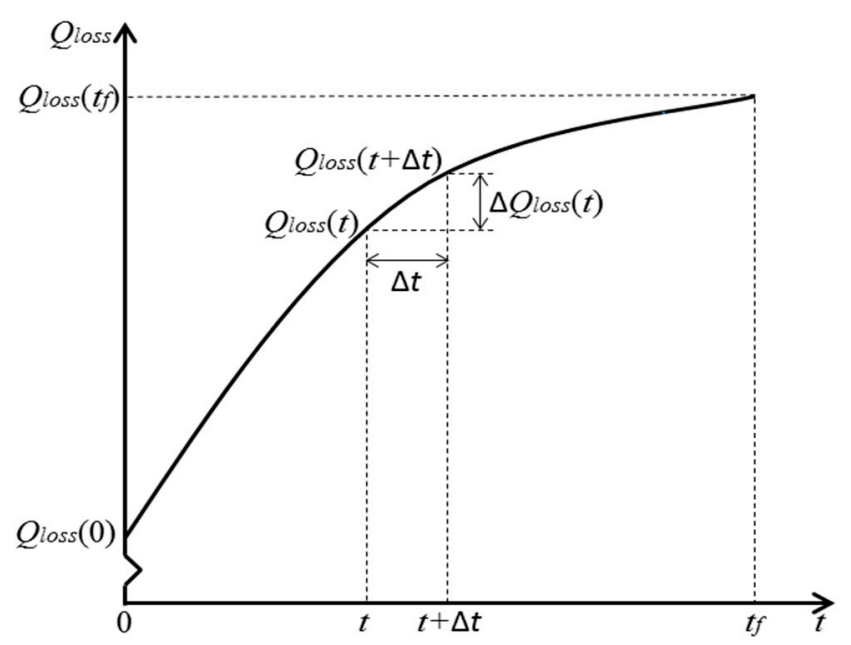

Figure 1. The variation tendency of a battery capacity loss during actual operating conditions.

The value of $z$ is 0.5 and the constants $M_{1}$ and $M_{2}$ are given as [14]

$$
M_{1}=B e^{\left(\frac{-31700}{R T}\right)}, \quad M_{2}=\frac{370.3}{S_{0} R T}
$$

Over time $\Delta t$, the loss of the battery capacity is shown as

$$
Q_{\text {loss }}(t+\Delta t)=M_{1} e^{M_{2} i(t)}\left[\overline{A_{h}}(t+\Delta t)\right]^{0.5}
$$


$\Delta t$ is supposed to approach to 0 , and the battery current $i(t)$ is a certain value in the time $\Delta t$. According to Equations (2)-(4), the above equation can be converted to

$$
\begin{aligned}
Q_{\text {loss }}(t+\Delta t) & =M_{1} e^{M_{2} i(t)}\left[\overline{A_{h}}(t)+\Delta A_{h}(t)\right]^{0.5} \\
& =M_{1} e^{M_{2} i(t)}\left[\frac{Q_{\text {loss }}^{2}(t)}{M_{1}^{2} e^{2 M_{2} i(t)}}+\frac{i(t)}{3600} \Delta t\right]^{0.5}
\end{aligned}
$$

Using Taylor expansion at $\Delta t=0$ and ignoring the higher order items of $\Delta t$, the $Q_{\text {loss }}(t+\Delta t)$ can be reformulated as

$$
Q_{\text {loss }}(t+\Delta t)=Q_{\text {loss }}(t)+\frac{M_{1} e^{2 M_{2} i(t)} i(t)}{7200 Q_{\text {loss }}(t)} \Delta t
$$

For a process with a very short duration, it can be assumed that the change in the decline rate of the total battery capacity will be small, that is, $Q_{\text {loss }}(t) \approx Q_{\text {loss }}\left(t_{0}\right)$; therefore, the battery capacity loss can be written as

$$
\Delta Q_{\text {loss }}(t)=\frac{M_{1} e^{2 M_{2} i(t)} i(t)}{7200 Q_{\text {loss }}(t)} \Delta t
$$

Obviously, the percentage of battery capacity loss from $t_{0}$ to $t$ under actual operating conditions can be represented as

$$
Q_{\text {loss }}(t)=\frac{M_{1}^{2}}{7200 Q_{\operatorname{loss}\left(t_{0}\right)}} \int_{t_{0}}^{t_{f}} e^{2 M_{2} i(t)} i(t) d t
$$

\section{Speed Planning Problem Formulation}

The vehicle speed trajectory under urban conditions generally includes three stages of acceleration, cruising, and deceleration. According to the analysis of the factors affecting the aging of the battery, the charge and discharge rate, cycling time, depth of discharge, and temperature will affect the aging of the battery. Different speed trajectories of electric vehicles will lead to different charge or discharge rates of the power battery, which in turn will result in different discharge depths. That is, different speed trajectories correspond to different battery aging amounts, so there is an optimal speed trajectory for optimizing the vehicle's target performance. The optimization objective of this paper is to minimize the total cost including battery energy consumption cost and life loss cost, so the optimal control problem is established as follows [31]:

$$
\begin{aligned}
& \min J=\varphi\left(x\left(t_{f}\right), t_{f}\right)+\int_{t 0}^{t f} L(x(t), u(t), t) d t \\
& \text { s.t. } \quad \dot{x}(t)=f(x(t), u(t), t) \\
& \quad C(x(t), u(t), t) \leq 0 \\
& \quad x\left(t_{0}\right)=x_{0}, \Phi\left(x\left(t_{f}\right), t_{f}\right)=0
\end{aligned}
$$

where $x(t)$ means state variable, $u(t)$ means control variable, J is objective function, $\mathrm{L}(x(t), u(t), t)$ is an integral function, $\mathrm{C}(x(t), u(t), t)$ is the inequality constraint, and $\Phi$ is the terminal condition.

During driving, the vehicle is affected by various forces in the direction of travel, and these forces can be divided into driving force and resistance, wherein the resistance includes rolling resistance, slope resistance, air resistance, and acceleration resistance. The dynamic equation of the vehicles is shown in Equation (12) [32],

$$
\frac{T_{m} i_{g} i_{0}}{r}=m g(f \cdot \cos \alpha+\sin \alpha)+\frac{1}{2} \rho C_{D} A v^{2}+\delta m \frac{d v}{d t}
$$

Among them, $T_{m}$ is the motor torque and the efficiency map of an electric motor is shown in Figure $2, i_{g}$ is the transmission ratio, $i_{0}$ is the final drive ratio, $r$ is the wheel radius, $g$ is the gravity acceleration, $f$ is the rolling resistance coefficient, $\alpha$ is the road gradient, $\rho$ is the air density, $C_{D}$ is 
vehicle air resistance coefficient. $A$ is the vehicle face area, $v$ is the vehicle speed, and $\delta$ is the rotating mass conversion factor and is generally 1 . Moreover, the main technical parameters of the vehicle are shown in Table 1.

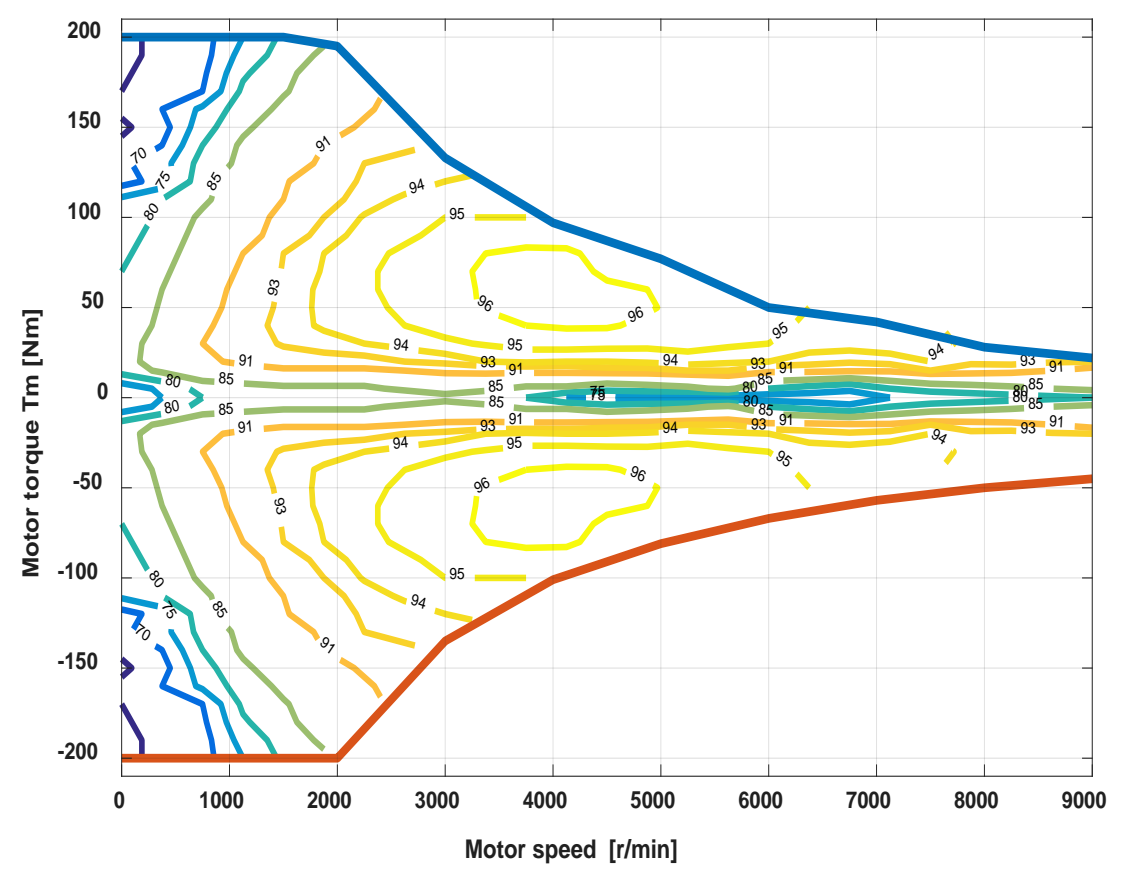

Figure 2. Efficiency map of an electric motor.

Table 1. The main technical parameters of the two-speed pure electric vehicle.

\begin{tabular}{ccc}
\hline Symbol & Description & Value [Unit] \\
\hline$m$ & Mass & $1500[\mathrm{~kg}]$ \\
$A$ & Face area & $2.08\left[\mathrm{~m}^{2}\right]$ \\
$C_{D}$ & Air resistance coefficient & 0.36 \\
$\rho$ & Air density & $1.205\left[\mathrm{~kg} / \mathrm{m}^{3}\right]$ \\
$f$ & Rolling resistance coefficient & 0.011 \\
$i_{0}$ & Final drive ratio & 4.2 \\
$r$ & Wheel radius & $0.33[\mathrm{~m}]$ \\
$i_{g 10}$ & First gear ratio & 3.17 \\
$i_{g 20}$ & Second gear ratio & 1.21 \\
\hline
\end{tabular}

For the above-mentioned economical driving speed optimization control problem, this paper selects the motor torque $T_{m}$ and gear $i_{g}$ as the control variable, that is, $u=\left[T_{m}, i_{g}\right]^{T}$, and selects the vehicle speed $v$ and the vehicle driving distance $s$ as the state variables, that is, $x=[\mathrm{v}, \mathrm{s}]^{T}$. So, the state equation can be expressed as

$$
\begin{aligned}
& \dot{v}(t)=\frac{1}{m}\left(\frac{T_{m}(t) i_{g} i_{0}}{r}-\frac{1}{2} \rho C_{D} A v^{2}(t)\right)-c_{r} g \\
& \dot{s}(t)=v(t)
\end{aligned}
$$

where $c_{r}$ is relevant to the coefficient of rolling resistance and slope resistance. $c_{r}=f \cos \alpha+\sin \alpha$.

Currently, the economic indicators of electric vehicles mainly refer to battery energy consumption. The aim of the economical speed optimization strategy is to minimize the total cost of the vehicle during travel. In this paper, considering that the power battery is the most expensive component in 
electric vehicles, the economic indicators will include the energy consumption and the life loss of the battery during use. Therefore, the cost function J is shown in Equation (14),

$$
J=\int_{t_{0}}^{t_{f}} P_{b}(t) d t+\alpha c_{a} \frac{M_{1}^{2}}{7200 Q_{\text {loss }\left(t_{0}\right)}} \int_{t_{0}}^{t_{f}} e^{2 M_{2} i(t)} i(t) d t
$$

In the formula, $P_{b}(t)$ is the instantaneous power of the battery, representing the energy consumption. $\alpha$ is the weighting factor, which represents the weight ratio between the battery energy consumption and the battery life loss in the integral function. $c_{a}$ is the conversion coefficient of battery life loss, which matches the life loss of the battery in quantity with the energy consumption of the battery and has the actual physical meaning. $\sigma$ is the severity factor describing the relative aging effect of the dynamic operating conditions of the battery relative to the nominal conditions.

In this paper, the conversion coefficient of battery life loss $c_{a}$ is defined as the ratio of the replacement cost per unit capacity of electric vehicle power battery to the $1 \mathrm{kWh}$ electricity cost. Table 2 lists the capacity and price of four pure electric vehicles power battery and calculates the value of the conversion coefficient of battery life loss and the cost of the $1 \mathrm{kWh}$ electricity is observed in the ordinary outdoor charging station According to the values in Table 2, $c_{a}=1100$ is taken in this paper.

Table 2. Conversion coefficient of battery life loss $c_{a}$ for four pure electric vehicles.

\begin{tabular}{ccccc}
\hline Vehicle Type & $\begin{array}{c}\text { Battery Pack } \\
\text { Price (RMB) }\end{array}$ & $\begin{array}{c}\text { Battery Pack } \\
\text { Capacity (kWh) }\end{array}$ & $\begin{array}{c}\text { 1 kWh Electricity } \\
\text { Cost (RMB) }\end{array}$ & $\boldsymbol{c}_{\boldsymbol{a}}$ \\
\hline BYD e5 450 & 100 thousand & 60 & 1.495 & 1114.8 \\
Roewe ERX5 & 80 thousand & 48.3 & 1.495 & 1107.9 \\
NIO ES8 & 100 thousand & 70 & 1.495 & 955.6 \\
Geely EV450 & 80 thousand & 51.9 & 1.495 & 1031.1 \\
\hline
\end{tabular}

Next, the relationship between the objective function $\mathrm{J}$, the state variables $x(t)$, and the control variables $u(t)$ will be established. In order to simplify the calculation, a simple RC (Resistance Capacitance) equivalent circuit is used here, as shown in Figure 3. According to the power model of battery and the Ohm's law, Equation (15) can be obtained,

$$
\begin{aligned}
& P_{b 0}(t)=U I_{p a c k}(t) \\
& U=V_{o c}-I R_{0}
\end{aligned}
$$

where $P_{b 0}(t)$ is the input/output power of battery, $\mathrm{U}$ is the terminal voltage of the battery, $I_{\text {pack }}(t)$ is the charge/discharge current, $V_{o c}$ is the open circuit voltage of the battery pack, and $R_{0}$ is the equivalent internal resistance. Assuming that the single cells inside the battery pack have good consistency, the current of the single battery $i(t)$ can be given as [34]

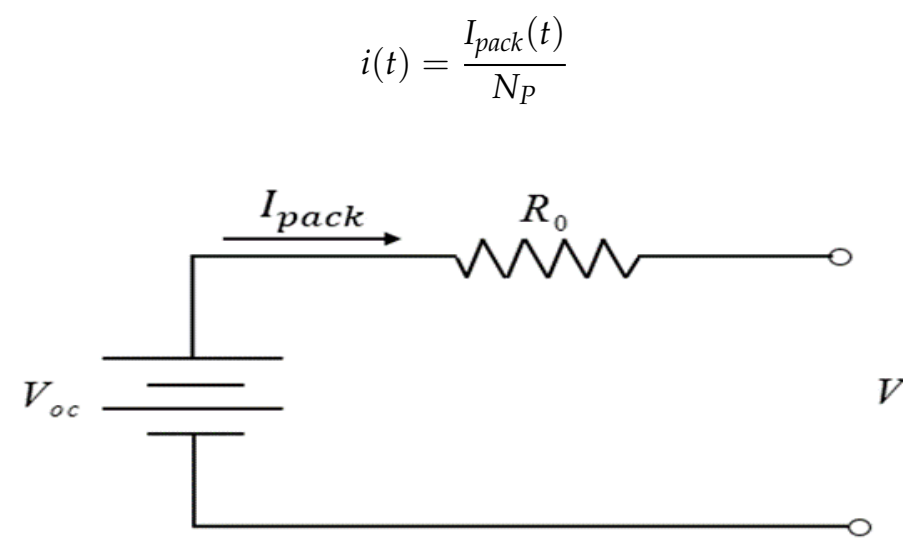

Figure 3. RC model of equivalent circuit of power battery. 
According to Equation (15), the relationship between the current and the instantaneous input/output power of the battery pack can be obtained, as shown in Equation (17),

$$
I_{\text {pack }}(t)=\frac{V_{o c}}{2 R_{0}}-\sqrt{\frac{V_{o c}^{2}}{4 R_{0}^{2}}-\frac{P_{b 0}(t)}{R_{0}}}
$$

In the general power system topology structure of electric vehicles, the output power of the battery will act on the drive motor through the inverter. The power relationship between the components of each power system is shown in Equation (18).

$$
\begin{array}{ll}
P_{b 0}(t)=\frac{P_{m}(t)}{\eta_{i v}(t) \eta_{m}(t)}, & T_{m} \geq 0 \\
P_{b 0}(t)=P_{m}(t) \cdot \eta_{i v}(t) \eta_{m}(t), & T_{m}<0 \\
P_{m}(t)=\frac{T_{m}(t) n_{m}(t)}{9550} &
\end{array}
$$

where $P_{m}(t)$ is the output/input power of motor, $\eta_{m}(t)$ is the instantaneous operating efficiency of motor, $\eta_{i v}(t)$ is the instantaneous operating efficiency of inverter, $T_{m}(t)$ is motor torque, and $n_{m}(t)$ is motor speed.

Therefore, the equation between current $i(t)$, motor torque $T_{m}$, gear $i_{g}$, and vehicle speed $v$ can be established by combining Equations (15)-(18), as

$$
I(t)=\frac{\frac{V_{o c}}{2 R_{0}}-\sqrt{\frac{V_{o c}^{2}}{4 R_{0}^{2}}-\frac{30 T_{m}(t) v(t) i_{g} i_{0}}{9550 \pi \eta_{i v}(t) \eta_{m}(t) R_{0} r}}}{N_{P}}
$$

In summary, we have established an explicit relationship among performance index function J, state variable $x(t)$, and control variable $u(t)$.

According to the actual physical significance of state variables and control variables in the optimal control of economic driving speed, the system has the following inequality constraints and boundary conditions,

$$
\begin{gathered}
v_{\min }(t) \leq v(t) \leq v_{\max }(t) \\
T_{m, \min } \leq T_{m}(t) \leq T_{m, \max } \\
i_{g} \in\{1,2\} \\
v\left(t_{0}\right)=v_{0}, s\left(t_{0}\right)=s_{0} \\
v\left(t_{f}\right)=v_{f}, s\left(t_{f}\right)=s_{f}
\end{gathered}
$$

Among them, $V_{\min }(t)$ and $V_{\max }(t)$ are the upper and lower limits of vehicles speed determined by the road signs, the vehicle ahead, and other traffic information. $v_{0}$ and $s_{0}$ are the initial speed and the vehicle travel distance, respectively, and $v_{f}$ and $s_{f}$ are the vehicle speed and travel distance at the terminal time, respectively.

\section{Solution}

Here, the economical driving velocity optimization control problem established in the previous section is converted into a nonlinear programming problem before it can be solved. Firstly, the optimal control problem is discretized into $N$ steps from time $t_{0}$ to $t_{f}$ in the time domain and $\Delta T$ means the interval time,

$$
x(k+1)=x(k)+f[x(k), u(k)] \Delta T
$$


Then, the speed optimal control problem established above can be written in the form of summation as follows

$$
\left\{\begin{array}{c}
\min J=\sum_{k=0}^{N+1} L(\bar{X}) \Delta T \\
X=[v(0), v(1), \ldots, x(N), s(0), s(1), \ldots, s(N)] \\
U=\left[T_{m}(0), T_{m}(1), \ldots, T_{m}(N), i_{g}(0), i_{g}(1), \ldots, i_{g}(N)\right]
\end{array}\right.
$$

where $N=\left(t_{f}-t_{0}\right) / \Delta T$. The control variable $u(t)$ and state variable $x(t)$ are redefined as a new state variable $\bar{X}=[X, U]$.

Therefore, the optimal control problem is transformed into a nonlinear programming problem, whose standard form is shown as follows,

$$
\begin{array}{lc}
\min J & =F(\bar{X}) \\
\text { s.t. } & h(\bar{X})=0 \\
& g(\bar{X}) \leq 0
\end{array}
$$

with

$$
\begin{aligned}
F(\bar{X}) & =\sum_{k=0}^{N+1} L[x(k), u(k)] \Delta T \\
g(\bar{X}) & =x(k)-x(k+1)+f[x(k), u(k)] \Delta T=0
\end{aligned}
$$

Finally, SQP (Sequential Quadratic Programming) algorithm is used to solve this nonlinear programming problem and the speed optimization control problem is solved.

\section{Analysis of Simulation Results}

In this section, on the basis of the established battery model and the economical speed optimization control problem, the simulation results of two different performance indicators, which only consider the battery energy consumption cost and comprehensively consider the battery energy consumption cost and battery aging cost, as well as the simulation results of two-speed electric vehicle and single-speed electric vehicle, are compared and analyzed. Finally, under the New European Driving Cycle (NEDC) and Urban Dynamometer Driving Schedule (UDDS) driving cycle conditions, the simulation results of two economic indicators of battery capacity decline and battery energy consumption were verified.

\subsection{Comparison and Analysis of Simulation Results of Different Performance Indicators}

According to the performance index expression, when $\alpha=0$, the performance index will only considers batteries energy consumption; when $\alpha=1$, the performance index will consider the energy consumption cost and the aging cost of batteries comprehensively. Then, the optimization simulation results of the two performance indicators are compared and analyzed. Setting up the simulation conditions, on a typical horizontal road between two intersections with a distance of $600 \mathrm{~m}$ in the urban area, the initial speed of the electric vehicle is zero, and then the driving conditions of acceleration, cruising, and deceleration are experienced. The time step is $0.5 \mathrm{~s}$, the initial SOC (state of charge) value of the battery is $80 \%$, the vehicle terminal speed is zero, and the temperature is $T=25^{\circ} \mathrm{C}$. The performance parameters of the two-speed gearbox are shown in Table 3 , where $i_{g i}=i_{g i 0} i_{0}$.

Table 3. Performance parameters of the two-speed gearbox.

\begin{tabular}{cc}
\hline Performance Parameters & Two-Speed Gearbox \\
\hline Transmission efficiency & $95 \%$ \\
Gear ratio & $i_{g 1}=13.31$ \\
& $i_{g 2}=5.08$ \\
\hline
\end{tabular}


Figure 4 shows the optimized velocity trajectories under different objective functions. Figure 5 shows some of the system states in the above simulation process, including motor torque, gearbox gear, and discharge current of the power battery pack.

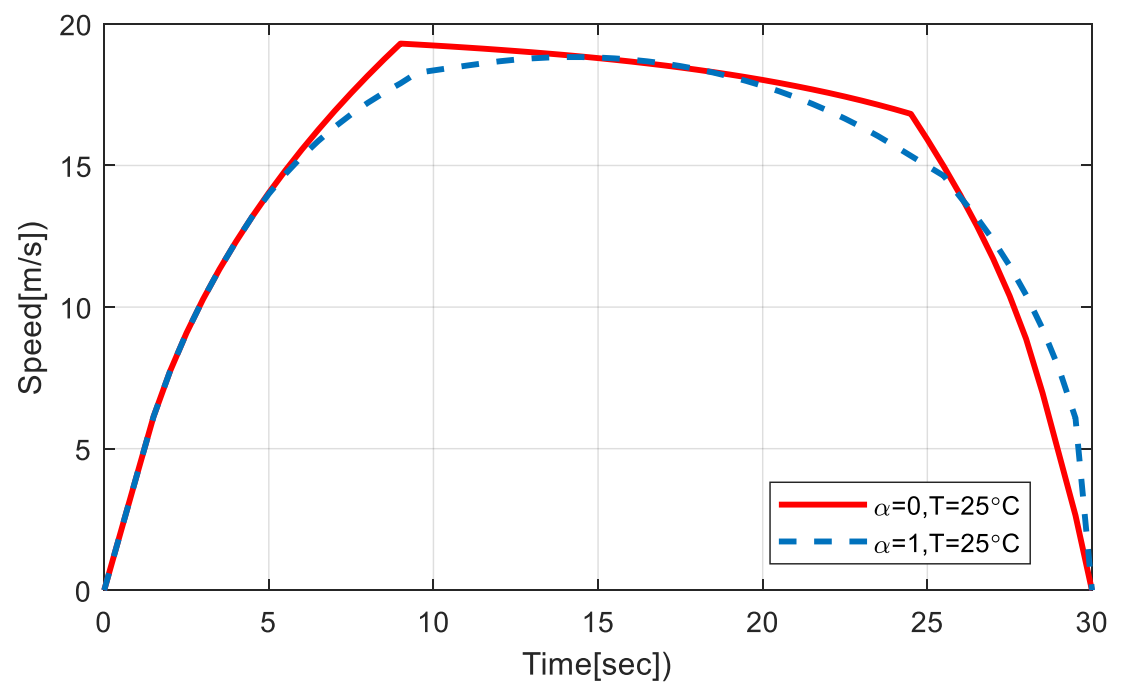

Figure 4. Comparison of speed trajectories under two cost functions ( $\alpha=1$ indicates that the battery life loss cost and the battery energy cost are comprehensively considered in the performance index; $\alpha=0$ means that only the battery energy cost is considered in the performance index).
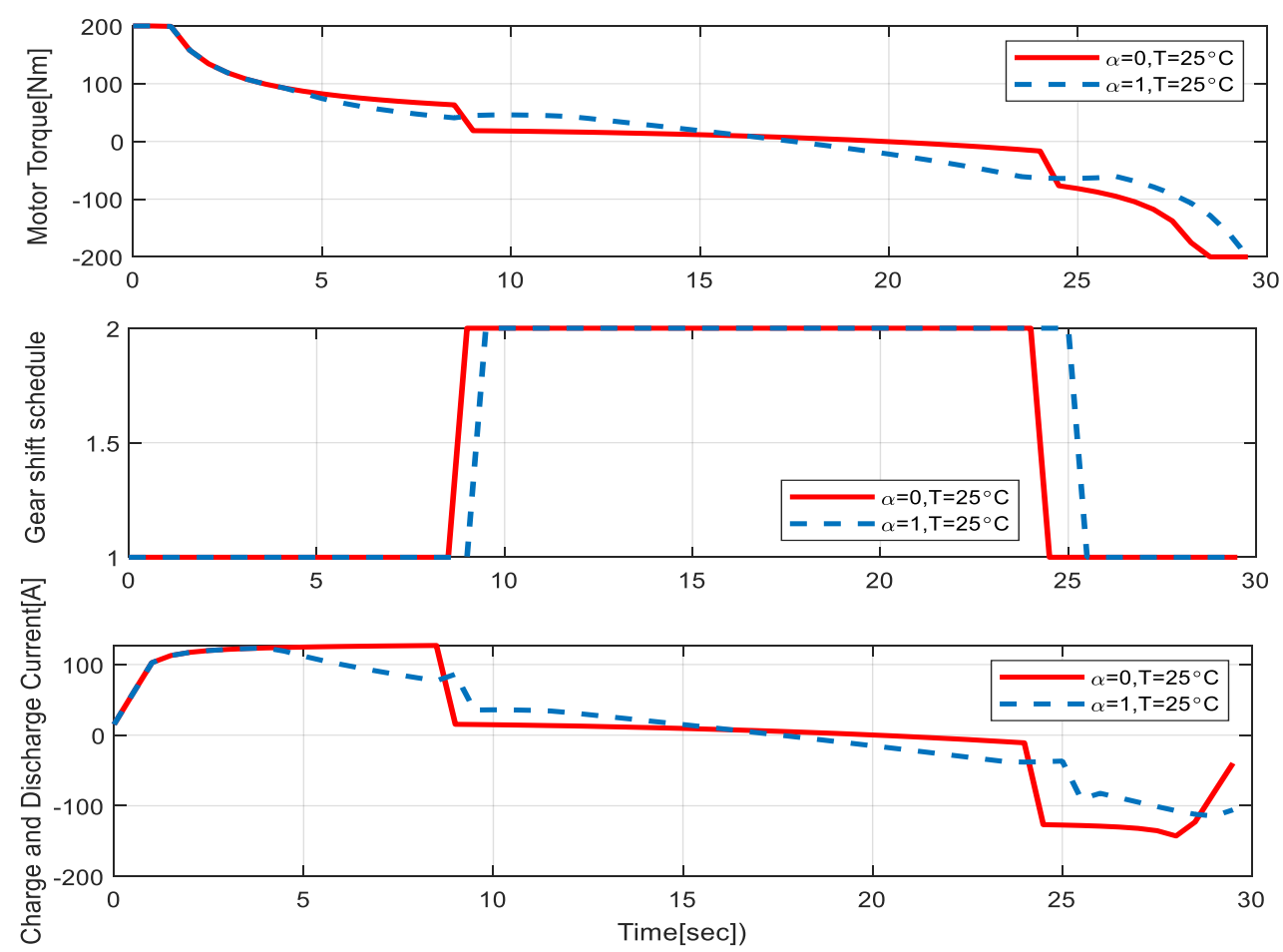

Figure 5. Comparison of system state trajectories under two cost functions ( $\alpha=1$ indicates that the battery life loss cost and the battery energy cost are comprehensively considered in the performance index; $\alpha=0$ means that only the battery energy cost is considered in the performance index).

Figure 6 shows the corresponding battery capacity degradation percentage and battery energy consumption. As can be seen from the figures, compared with the economic indicator considering battery energy consumption alone, the decline of battery capacity when considering both battery energy consumption cost and battery aging cost is significantly reduced, and the percentage of battery 
capacity decline is $0.0002086 \%$. While the decline of battery capacity when considering battery energy consumption alone is $0.0002647 \%$, the decline of battery capacity is reduced by $21.19 \%$. At the same time, as a cost, the battery energy consumption when considering the battery energy consumption and aging cost comprehensively is increased by $7.66 \%$ compared with that when considering the battery energy consumption alone. The specific simulation results are shown in Table 4.
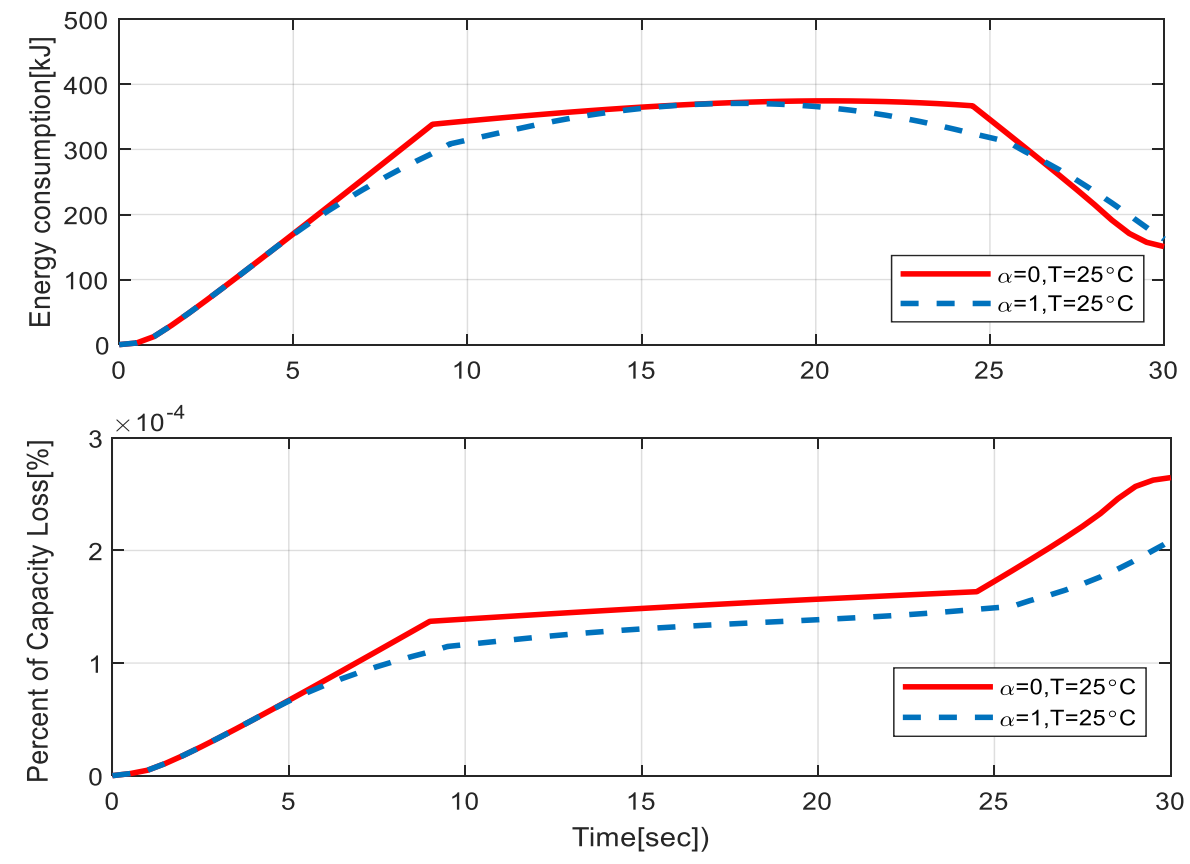

Figure 6. Capacity degradation and energy consumption simulation results of batteries under two cost functions ( $\alpha=1$ indicates that the battery life loss cost and the battery energy cost are comprehensively considered in the performance index; $\alpha=0$ means that only the battery energy cost is considered in the performance index).

Table 4. Simulation results of different cost functions.

\begin{tabular}{ccc}
\hline Symbol & Value [Unit] & Comparison \\
\hline$W_{\alpha=0}$ & $150.63[\mathrm{~kJ}]$ & Increasing $7.66 \%$ \\
$W_{\alpha=1}$ & $162.17[\mathrm{~kJ}]$ & \\
\hline$Q_{\alpha=0}$ & $0.0002647 \%$ & Reducing $21.19 \%$ \\
$Q_{\alpha=1}$ & $0.0002086 \%$ & \\
\hline
\end{tabular}

In summary, when the unified conversion to the currency standard, comprehensive consideration of battery energy consumption cost and battery aging cost shows better economics.

\subsection{Comparison and Analysis of Simulation Results between Two-Gear Electric Vehicle and Single-Gear Electric Vehicle}

The simulation object of this paper is an electric vehicle with two-gear non-power interruption gearbox. Compared with the electric vehicle with single-speed transmission, a two-gear gearbox has a positive effect on delaying the battery life decline and reducing the battery energy consumption of the electric vehicles. The performance parameters of the one-speed gearbox and two-speed gearbox are shown in Table 5. This subsection will make a comparative analysis of the two gearboxes. 
Table 5. Performance parameters of the one-speed and two-speed gearbox.

\begin{tabular}{ccc}
\hline Performance Parameters & Single-Speed Gearbox & Two-Speed Gearbox \\
\hline Gear ratio & $i_{g}=10.21$ & $\begin{array}{c}i_{g 1}=13.31 \\
i_{g 2}=5.08\end{array}$ \\
\hline
\end{tabular}

Referring to the author's existing results [13], the final drive ratio of the single-speed electric vehicle is set to 10.21, and the other vehicle parameters are the same. A comparative analysis of battery life decline and battery energy consumption between two kinds of transmission is performed. Figure 7 shows the optimized velocity trajectories of single-gear and two-gear electric vehicle. Figure 8 shows some of the system states during the above simulation, including motor torque and power pack discharge current.

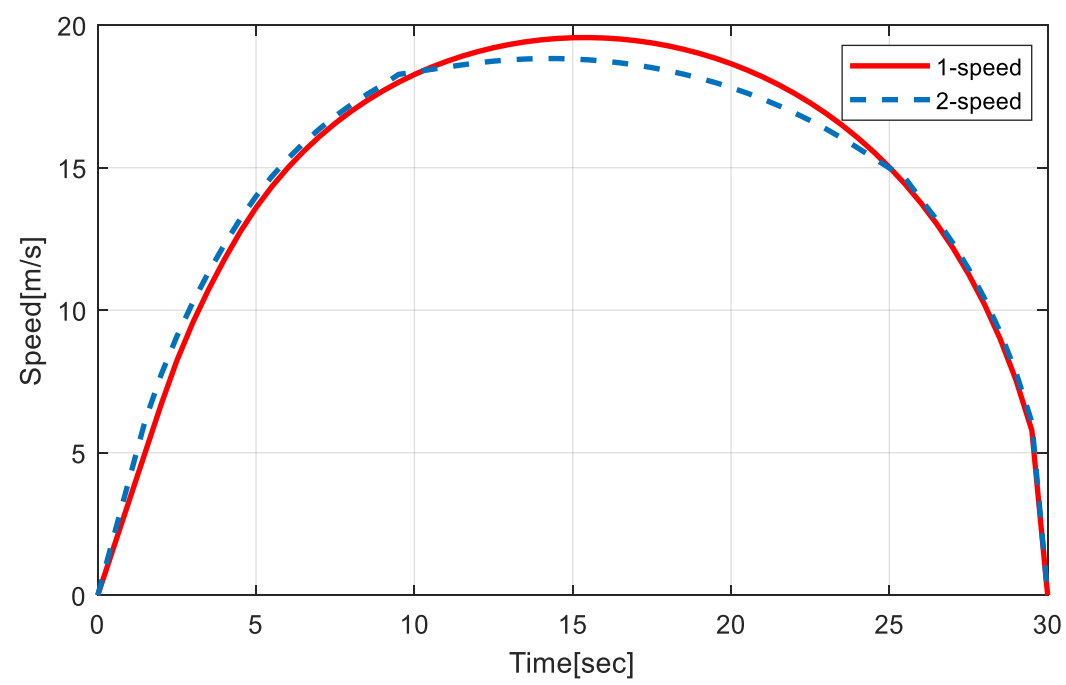

Figure 7. Comparison of speed trajectories under different gearboxes.
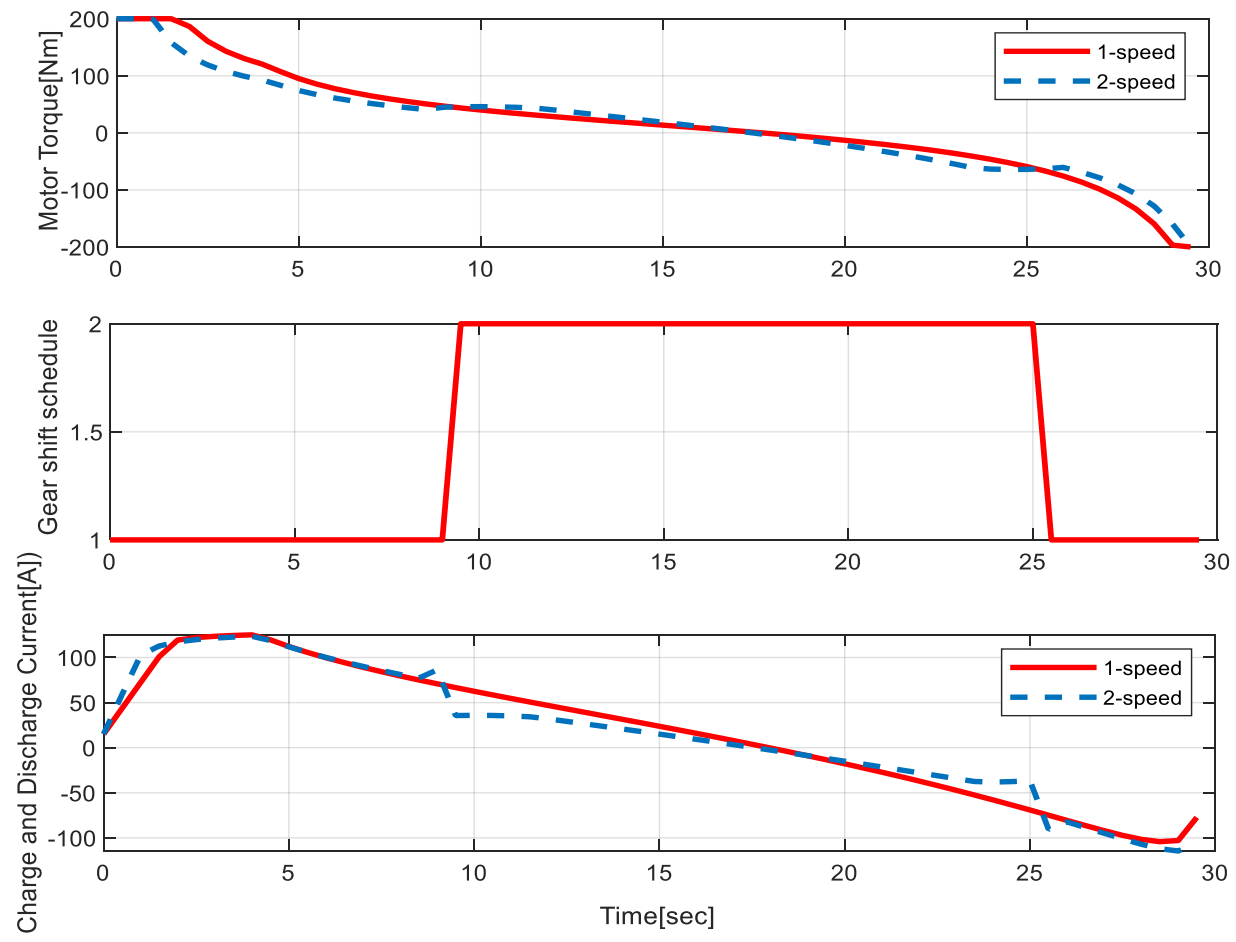

Figure 8. Comparison of system state trajectories under different gearboxes. 
Figure 9 shows the percentage of battery capacity loss and battery energy consumption. As can be seen from the figure, compared with the single-speed electric vehicles, the two-speed gearbox reduces both battery capacity degradation and battery energy consumption; its battery capacity decline is $0.0002086 \%$, while the battery capacity decline with the single-speed electric vehicles is $0.0002191 \%$. Therefore, the unpowered two-speed gearbox can reduce battery capacity degradation by $4.79 \%$. At the same time, the energy consumption of the two-speed gearbox electric vehicle is also lower than that of the single-speed gearbox electric vehicle, and the battery energy consumption is reduced by $8.70 \%$. The specific simulation result values are shown in Table 6.
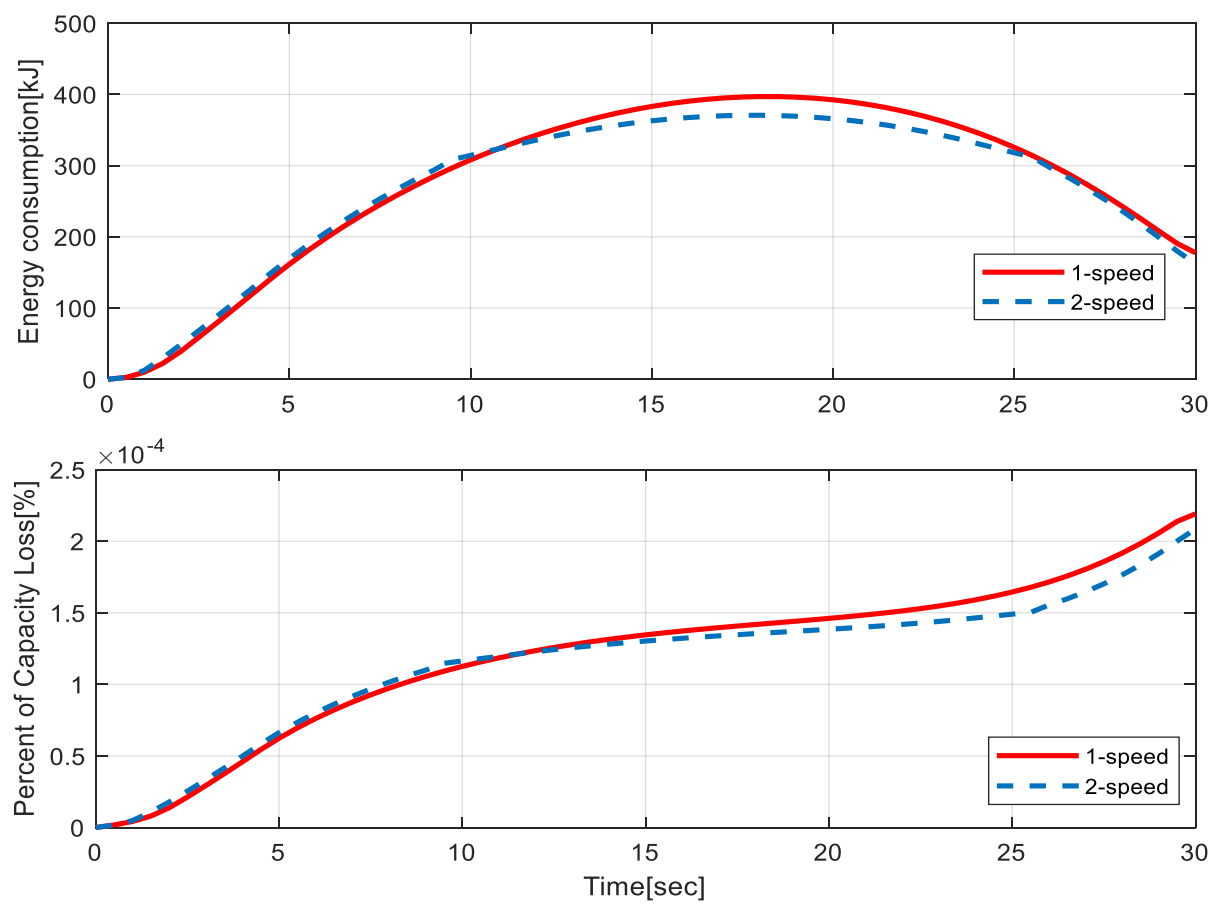

Figure 9. Capacity degradation and energy consumption simulation results of batteries with different gearboxes.

Table 6. Simulation results of different gearboxes.

\begin{tabular}{ccc}
\hline Symbol & Value [Unit] & Comparison \\
\hline$W_{1 \text {-speed }}$ & $177.63[\mathrm{~kJ}]$ & Reducing $8.70 \%$ \\
$W_{2 \text {-speed }}$ & $162.17[\mathrm{~kJ}]$ & \\
\hline$Q_{1 \text {-speed }}$ & $0.0002191 \%$ & Reducing $4.79 \%$ \\
$Q_{2 \text {-speed }}$ & $0.0002086 \%$ & \\
\hline
\end{tabular}

\subsection{Simulation Verification of Driving Cycle Conditions}

In the above, the simulation results of the economic driving speed optimization control are compared and analyzed for different objective functions, two-speed gearbox electric vehicles with motor direct-drive electric vehicles, and different temperatures. As the simulation conditions are ideally set and there is no interference from other vehicle, in addition, the optimized speed trajectory has a rapid acceleration condition. Therefore, the condition setting does not have generality, which makes the simulation result distorted to a certain extent. Moreover, compared with the motor direct drive electric vehicles, the transmission efficiency of the two-speed gearbox electric vehicles will be reduced. The mechanical efficiency of the direct drive and two-speed gearbox electric vehicles is $95 \%$ in both cases. This section will verify the simulation results of the model under NEDC and UDDS cycle conditions. 


\subsubsection{NEDC Driving Cycle Conditions}

NEDC condition test standard is widely used in the test of the comprehensive driving range of pure electric vehicles. On this basis, this subsection will verify the positive effects of the two-speed gearbox electric vehicles compared with the motor direct drive electric vehicles in delaying battery life degradation and reducing battery energy consumption in the NEDC condition. The NEDC condition consists of two parts: the urban operation cycle and the suburban cycle. The urban cycle consists of four small-cycle units of $195 \mathrm{~s}$, including several stages of vehicle idle speed, start-up, acceleration, and deceleration parking. The suburban cycle time is $400 \mathrm{~s}$, and the maximum speed is $120 \mathrm{~km} / \mathrm{h}$, as shown in Figures 10 and 11, showing some of the system states during the above simulation, including motor torque, gear of two gearboxes, and discharge current of battery pack.

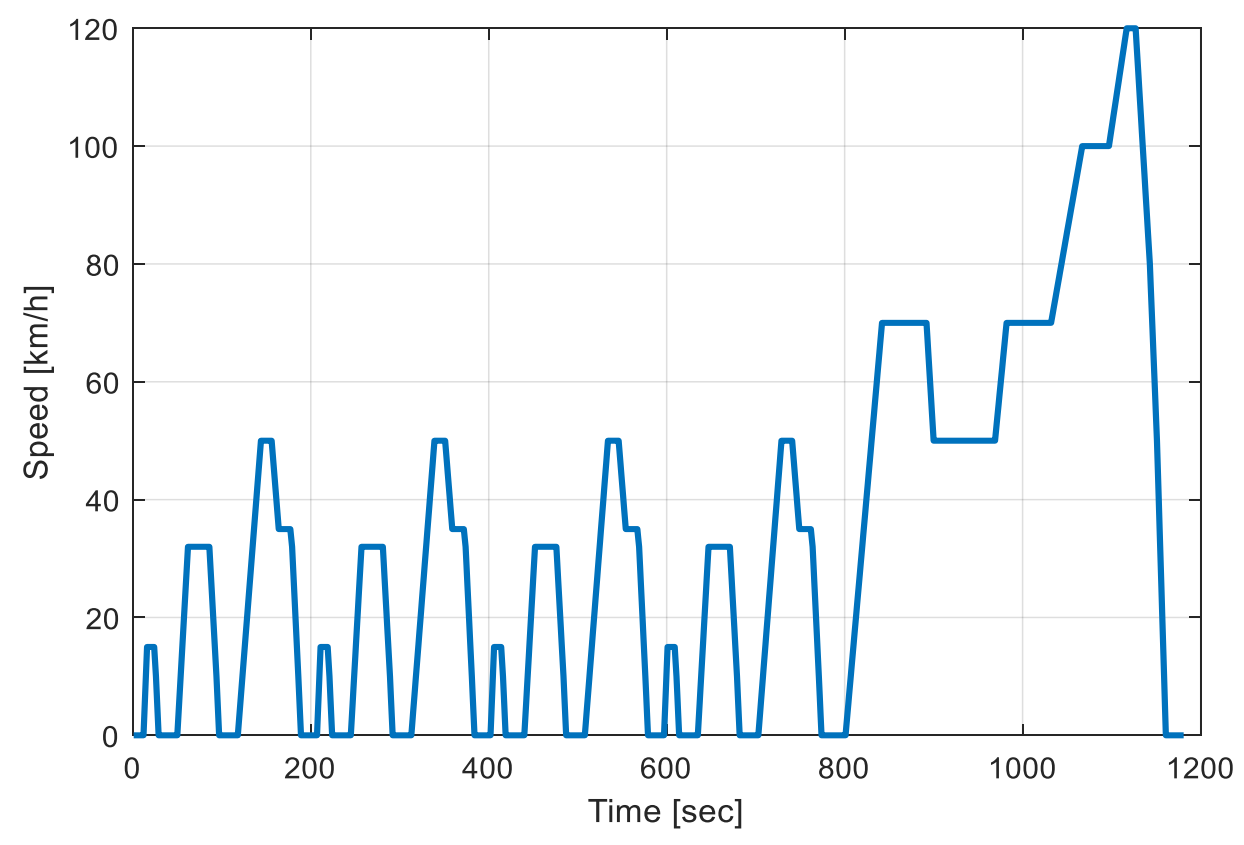

Figure 10. New European Driving Cycle (NEDC) condition.

Figure 12 shows the percentage of battery capacity loss and battery energy consumption under the corresponding working conditions. As can be seen from the figure, under the NEDC condition, compared with the direct-drive electric vehicle, the two-gear transmission reduces both the battery capacity degradation and battery energy consumption. Its battery capacity decline is $0.002237 \%$, while the battery capacity decline under the direct-drive of the motor is $0.002391 \%$. Therefore, the battery capacity decline can be reduced by $6.44 \%$ by the two-gear transmission without a power interruption. At the same time, the energy consumption of the two-speed gearbox electric vehicle is also lower than that of the motor direct-drive electric vehicle, and the battery energy consumption is reduced by $3.17 \%$. The specific simulation result values are shown in Table 7.

Table 7. Simulation results of different gearboxes under New European Driving Cycle (NEDC) conditions.

\begin{tabular}{ccc}
\hline Symbol & Value [Unit] & Comparison \\
\hline$W_{1 \text {-speed }}$ & $4380.55[\mathrm{~kJ}]$ & Reducing $3.17 \%$ \\
$W_{2 \text {-speed }}$ & $4241.51[\mathrm{~kJ}]$ & \\
\hline$Q_{1 \text {-speed }}$ & $0.002391 \%$ & Reducing $6.44 \%$ \\
$Q_{2 \text {-speed }}$ & $0.002237 \%$ & \\
\hline
\end{tabular}



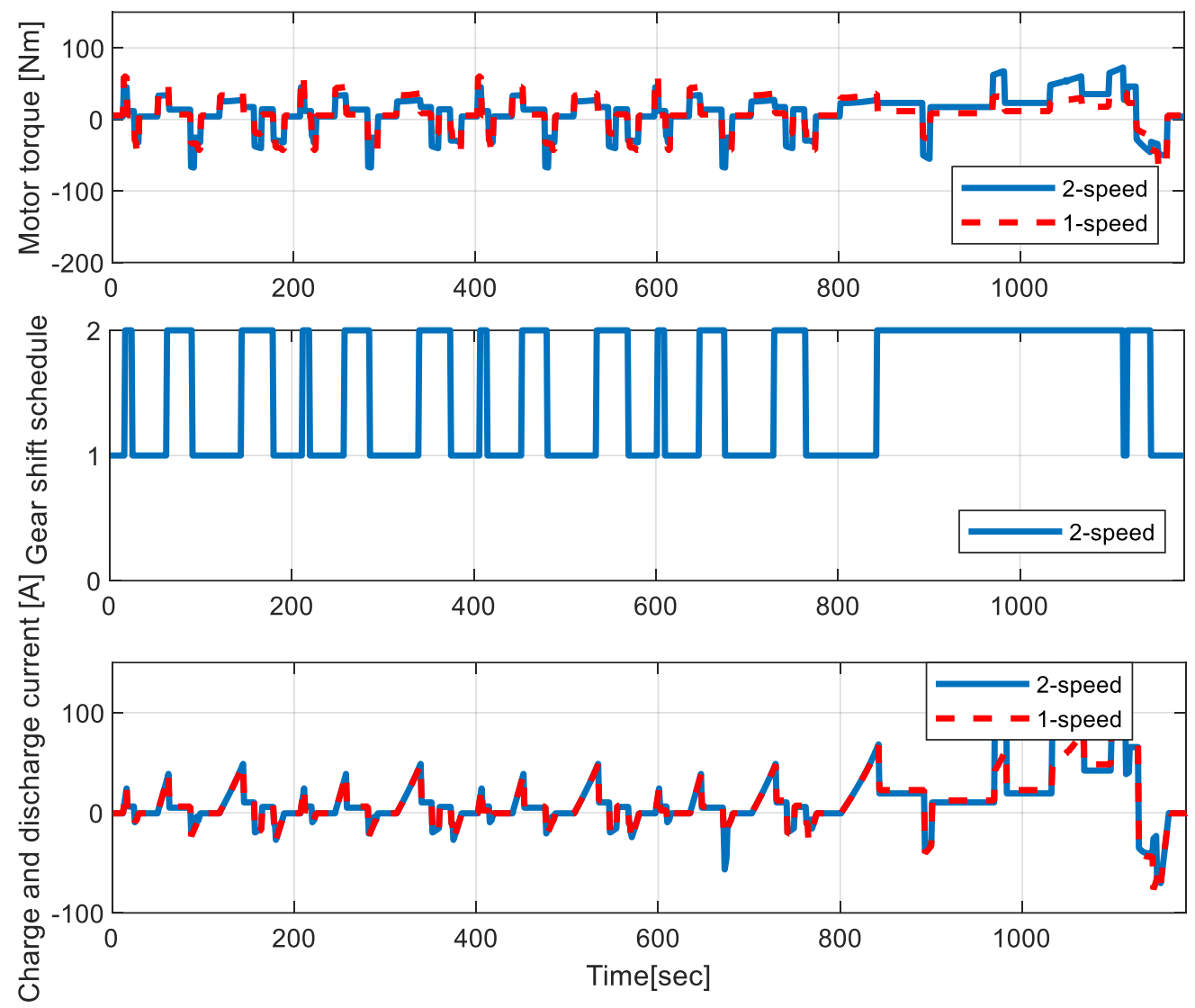

Figure 11. Comparison of system state trajectories of two gearboxes under NEDC cycle conditions.
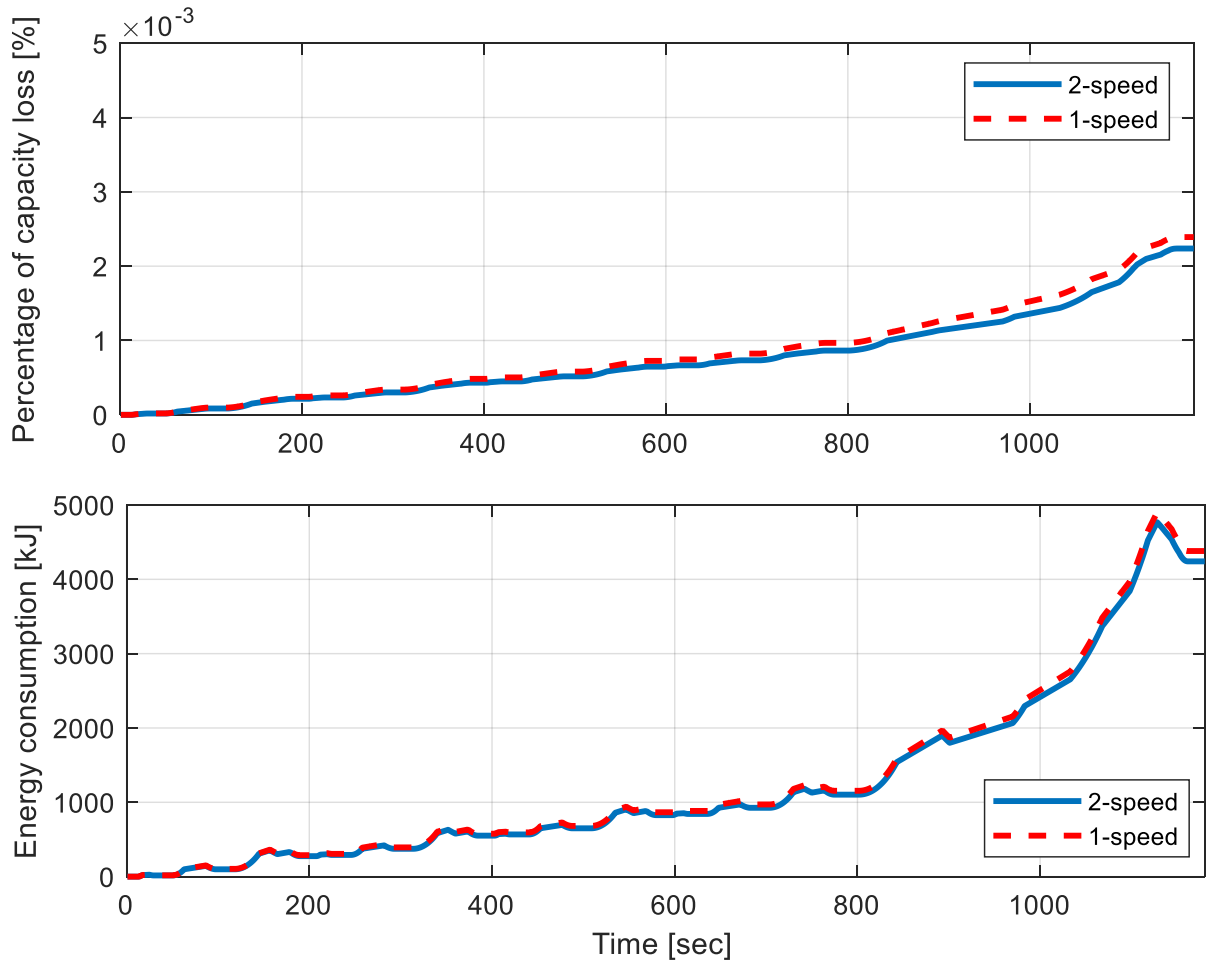

Figure 12. Simulation results of battery capacity loss percentage and energy consumption under NEDC conditions. 


\subsubsection{UDDS Driving Cycle Conditions}

Because most of the working conditions of NEDC are at constant speed and the working conditions of four small units in urban areas are identical, while the driving conditions of electric vehicles in urban environment are relatively disordered, the driving conditions of NEDC may not truly reflect the driving conditions of vehicles in the actual urban environment. In this subsection, the UDDS condition, as shown in Figure 13, is used for further simulation verification. Figure 14 shows some system states in the above simulation process, including motor torque, gear sequence of two gearbox, and discharge current of battery pack.

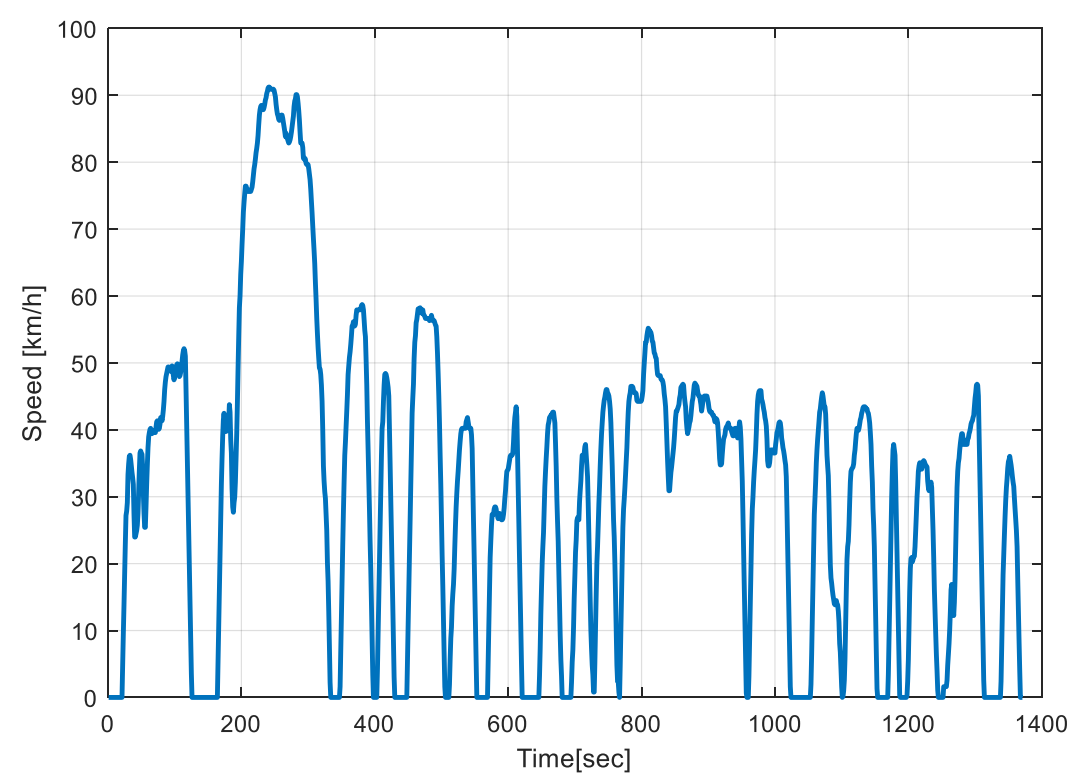

Figure 13. Urban Dynamometer Driving Schedule (UDDS) condition.
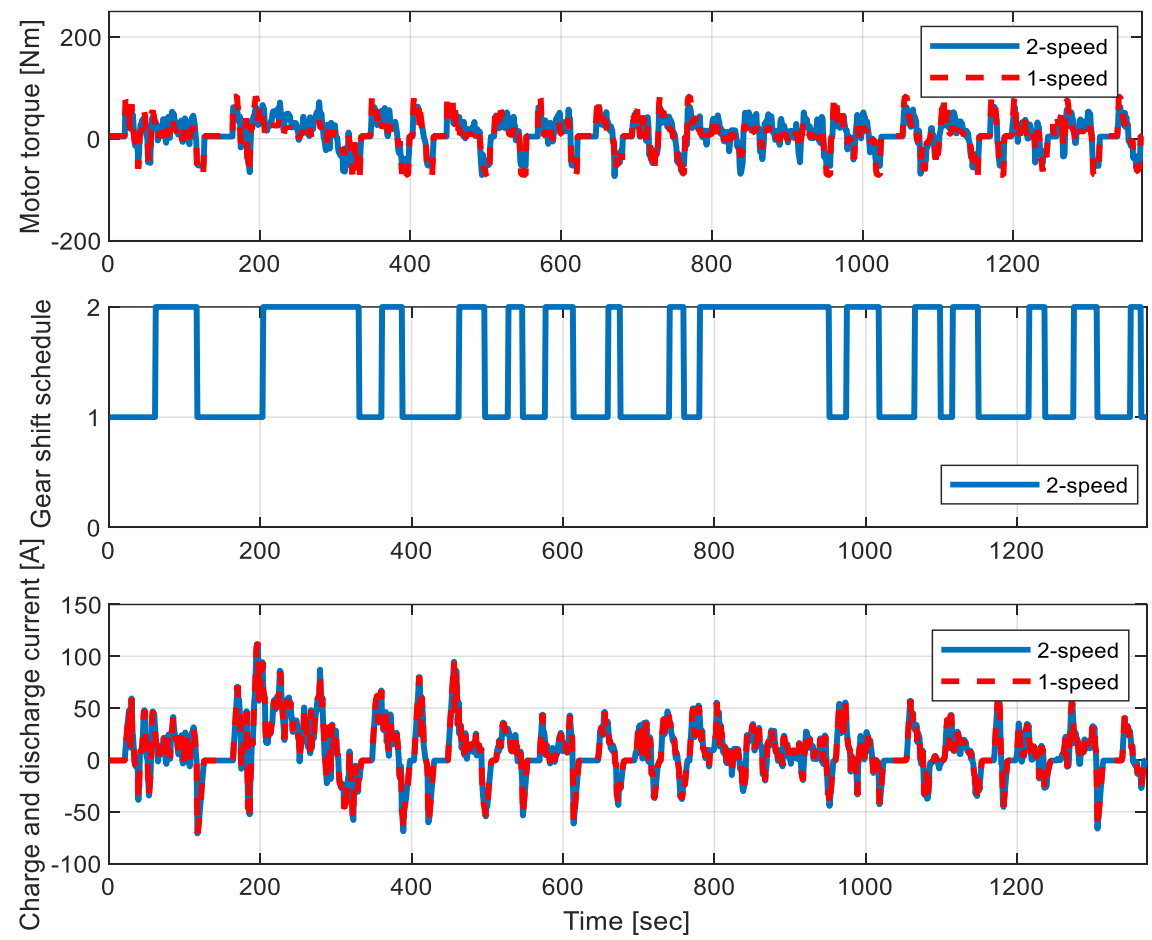

Figure 14. Comparison of system state trajectories of two gearboxes under UDDS cycle conditions. 
Figure 15 shows the percentage of battery capacity loss and battery energy consumption under the UDDS condition. It can be seen from the figure that, under the UDDS condition, compared with direct-drive electric vehicle, two-gear transmission reduces both battery capacity degradation and battery energy consumption. Its battery capacity decline is $0.002610 \%$, while that under direct-drive electric vehicle is $0.002867 \%$. Therefore, the battery capacity decline can be reduced by $8.96 \%$ by two-gear transmission without a power interruption. At the same time, the energy consumption of the two-speed gearbox electric vehicle is also lower than that of the motor direct-drive electric vehicle, and the battery energy consumption is reduced by $4.36 \%$. The specific values are shown in Table 8 .
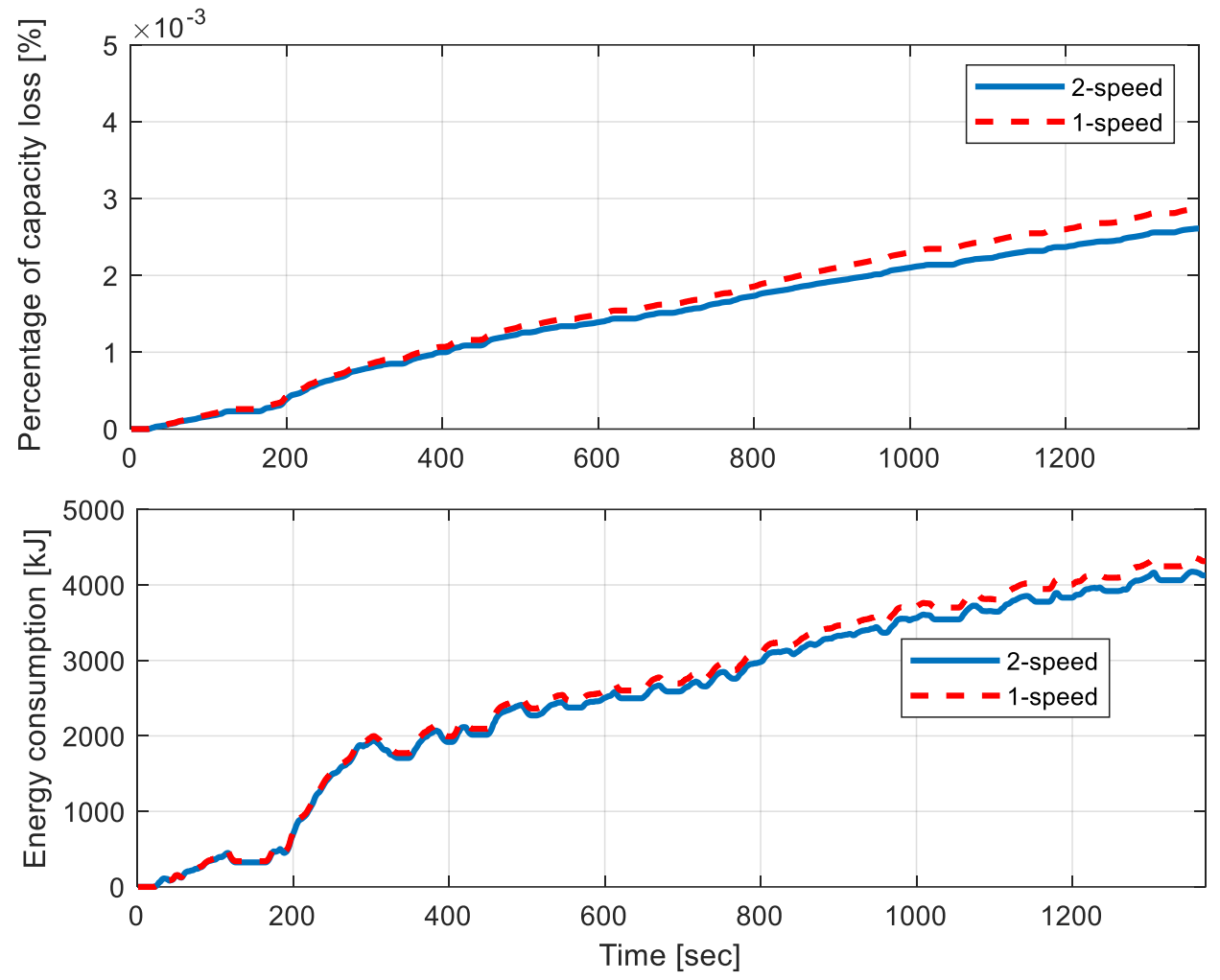

Figure 15. Simulation results of battery capacity loss percentage and energy consumption under UDDS conditions.

Table 8. Simulation results of different gearboxes under Urban Dynamometer Driving Schedule (UDDS) conditions.

\begin{tabular}{ccc}
\hline Symbol & Value [Unit] & Comparison \\
\hline$W_{1 \text {-speed }}$ & $4314.84[\mathrm{~kJ}]$ & Reducing $4.36 \%$ \\
$W_{2 \text {-speed }}$ & $4126.85[\mathrm{~kJ}]$ & \\
\hline$Q_{1 \text {-speed }}$ & $0.002867 \%$ & Reducing $8.96 \%$ \\
$Q_{2 \text {-speed }}$ & $0.002610 \%$ & \\
\hline
\end{tabular}

\section{Conclusions}

This paper focuses on the energy optimization problem of two-speed electric vehicles. Under the background of the high price of electric vehicle power battery, this paper supplements the economic indicators of electric vehicles, and takes the aging cost of battery as a part of the economic indicators of electric vehicles. By comparing with the optimization results considering the economic index of battery energy consumption alone, it is concluded that considering battery life is of great significance to the economy of electric vehicles. In addition, compared with the single-speed transmission, the 
influence of the two-speed gearbox on the economy of the electric vehicles and its application potential are analyzed.

The results show that the battery life can be increased by $21.19 \%$ when the aging cost of the battery is considered in the economic index, compared with the economic index of pure battery energy consumption under a set $600 \mathrm{~m}$ acceleration-cruise-deceleration driving scenario. Under the same scenario, compared with one-speed drive electric vehicles, the two-speed gearbox has $8.70 \%$ saving in energy consumption and $4.79 \%$ saving in battery aging. At the same time, under NEDC and UDDS conditions, compared with direct drive electric vehicles, the two-speed gearbox has a positive effect on delaying the battery life decline and reducing battery energy consumption of electric vehicles, which can reduce the battery capacity decline by $6.44 \%$ and $8.96 \%$, and the battery energy consumption by $3.17 \%$ and $4.36 \%$, respectively. It is shown that, whether in the acceleration-deceleration driving between two intersections or in normal driving cycles, the two-speed gearbox has obvious application potential in electric vehicles.

Author Contributions: Data curation, B.G.; formal analysis, Y.L.; investigation, X.S.; Simulation Validation, H.C.; Supervision, B.G. All authors have read and agreed to the published version of the manuscript.

Funding: This work was supported by the China Automobile Industry Innovation and Development Joint Fund (No. U1664257), National Nature Science Foundation of China (No. 61790564), and State Key Laboratory of Comprehensive Technology on Automobile Vibration and Noise \& Safety Control (W65-GNZX-2018-0242).

Conflicts of Interest: The authors declare no conflict of interest.

\section{References}

1. Prakash, G.K.; Olah, G.; Goeppert, A. Beyond Oil and Gas: The Methanol Economy. ECS Trans. 2011, 35, 31-40. [CrossRef]

2. Swami, A. Impact of Automobile Induced Air Pollution on road side vegetation: A Review. ESSENCE Int. J. Environ. Rehab. Conserv. 2018, 9, 101-116. [CrossRef]

3. Zhang, L.; Qin, Q. China's new energy vehicle policies: Evolution, comparison and recommendation. Transport. Res. A Policy Pract. 2008, 110, 57-72. [CrossRef]

4. Zubi, G.; Dufo-López, R.; Carvalho, M.; Pasaoglu, G. The lithium-ion battery: State of the art and future perspectives. Renew. Sustain. Energy Rev. 2018, 89, 292-308. [CrossRef]

5. Shi, C.; Zhu, J.; Shen, X.; Chen, F.; Ning, F.; Zhang, H.; Long, Y.; Ning, X.; Zhao, J. Flexible inorganic membranes used as a high thermal safety separator for the lithium-ion battery. RSC Adv. 2018, 8, 4072-4077. [CrossRef]

6. Li, M.; Lu, J.; Chen, Z.; Amine, K. 30 years of lithium-ion batteries. Adv. Mater. 2018, 30, 1800561. [CrossRef]

7. Chakraborty, D.; Nandi, A.K. Finding optimal driving region of electric vehicles during acceleration. In Proceedings of the IEEE International Conference on Power Electronics, Drives and Energy Systems (PEDES), Sydney, Australia, 9-12 June 2015; pp. 1-6.

8. Wang, L.; Collins, E.G.; Li, H. Optimal design and real-time control for energy management in electric vehicles. IEEE Trans. Veh. Tech. 2011, 60, 1419-1429. [CrossRef]

9. Chen, H.; Guo, L.; Ding, H.; Li, Y.; Gao, B. Real-Time Predictive Cruise Control for Eco-Driving Taking into Account Traffic Constraints. IEEE Trans. Intell. Transp. Syst. 2018, 20, 2858-2868. [CrossRef]

10. Khayyam, H.; Bab-Hadiashar, A. Adaptive intelligent energy management system of plug-in hybrid electric vehicle. Energy 2014, 69, 319-335. [CrossRef]

11. Xiong, H.; Zhu, X.; Zhang, R. Energy recovery strategy numerical simulation for dual axle drive pure electric vehicle based on motor loss model and big data calculation. Complexity 2018, 1-14. [CrossRef]

12. Björnsson, L.H.; Karlsson, S. The potential for brake energy regeneration under Swedish conditions. Appl. Energy 2016, 168, 75-84. [CrossRef]

13. Najib, S.; Erdem, E. Current progress achieved in novel materials for supercapacitor electrodes: Mini review. Nanoscale Adv. 2019, 1, 2817-2827. [CrossRef]

14. Gao, B.; Guo, L.; Zheng, Q.; Huang, B. Acceleration Speed Optimization of Intelligent EVs in Consideration of Battery Aging. IEEE Trans. Veh. Tehchnol. 2018, 67, 8009-8018. [CrossRef] 
15. Yang, Z.; Pun-Cheng Lilian, S.C. Vehicle detection in intelligent transportation systems and its applications under varying environments: A review. Image Vis. Comput. 2018, 69, 143-154. [CrossRef]

16. Kumar, P.M.; Devi, G.U.; Manogaran, G.; Sundarasekar, R.; Chilamkurti, N.; Varatharajan, R. Ant colony optimization algorithm with Internet of Vehicles for intelligent traffic control system. Comput. Netw. 2018, 144, 154-162. [CrossRef]

17. Wang, J.; Liu, P.; Hicks-Garner, J.; Sherman, E.; Soukiazian, S.; Verbrugge, M.; Tataria, H.; Musser, J.; Finamore, P. Cycle-life model for graphite-LiFePO 4 cells. J. Power Sources 2011, 196, 3942-3948. [CrossRef]

18. Kabir, M.M.; Demirocak, D.E. Degradation mechanisms in Li-ion batteries: A state-of-the-art review. Int. J. Energ. Res. 2017, 41, 1963-1986. [CrossRef]

19. Pelletier, S.; Jabali, O.; Laporte, G.; Veneroni, M. Battery degradation and behaviour for electric vehicles: Review and numerical analyses of several models. Tran. Res. Part B Methodol. 2017, 103, 158-187. [CrossRef]

20. Pesaran, A.; Smith, K.; Markel, T. Impact of the 3Cs of batteries on PHEV value proposition: Cost, calendar life, and cycle life. In Proceedings of the Advanced Automotive Battery Conference, Long Beach, CA, USA, 10-12 June 2009; Available online: https://www.researchgate.net/publication/242112585 (accessed on 19 March 2019).

21. Onori, S.; Spagnol, P.; Marano, V.; Gywwnnwx, Y.; Rizzoni, G. A new life estimation method for lithium-ion batteries in plug-in hybrid electric vehicles applications. Int. J. Power Electron. 2012, 4, 302-319. [CrossRef]

22. Spagnol, P.; Onori, S.; Madella, N.; Guezennec, Y.; Neal, J. Aging and characterization of li-ion batteries in a HEV application for lifetime estimation. IFAC Proc. Vol. 2010, 43, 186-191. [CrossRef]

23. Omar, N.; Monem, M.A.; Firouz, Y.; Salminen, J.; Smekens, J.; Hegazy, O.; Gaulous, H.; Mulder, G.; Van den Bossche, P.; Coosemans, T.; et al. Lithium iron phosphate based battery-assessment of the aging parameters and development of cycle life model. Appl. Energy 2014, 113, 1575-1585. [CrossRef]

24. Ren, Q.; Crolla, D.A.; Morris, A. Effect of geared transmissions on electric vehicle drivetrains. In Proceedings of the ASME 2009 International Design Engineering Technical Conferences and Computers and Information in Engineering Conference, San Diego, CA, USA, 30 August-2 September 2009.

25. Goetz, M.; Levesley, M.C.; Crolla, D.A. Integrated powertrain control of gearshifts on twin clutch transmissions. In Proceedings of the 2004 SAE World Congress, Detroit, MI, USA, 8 March 2004. No. 2004-01-1637.

26. Sorniotti, A.; Subramanyan, S.; Turner, A.; Cavallino, C.; Viotto, F.; Bertolotto, S. Selection of the Optimal Gearbox Layout for an Electric Vehicle. SAE Int. J. Engines 2011, 4, 1267-1280. [CrossRef]

27. Sorniotti, A.; Pilone, G.L.; Viotto, F.; Bertolotto, S.; Everitt, M.; Barnes, R.; Morrish, I. A Novel Seamless 2-Speed Transmission System for Electric Vehicles: Principles and Simulation Results. SAE Int. J. Engines 2011, 4, 2671-2685. [CrossRef]

28. Schmalstieg, J.; Käbitz, S.; Ecker, M.; Sauer, D.U. A holistic aging model for Li (NiMnCo) $\mathrm{O}_{2}$ based 18650 lithium-ion batteries. J. Power Sources 2014, 257, 325-334. [CrossRef]

29. Narayanrao, R.; Joglekar, M.M.; Inguva, S. A Phenomenological Degradation Model for Cyclic Aging of Lithium Ion Cell Materials. J. Electrochem. Soc. 2013, 160, A125-A137. [CrossRef]

30. Christensen, J.; Newman, J. Stress generation and fracture in lithium insertion materials. J. Solid State Electrochem. 2006, 10, 293-319. [CrossRef]

31. Jason, L.; Speyer, D.; Jacobson, H. Primer on Optimal Control Theory. Adv. Des. Con. 2010, 21-22.

32. Wallentowitz, H. Automotive Engineering I: Longitudinal Dynamics of Vehicles; Wang, X., Ed.; China Machine Press: Beijing, China, 2009.

(C) 2020 by the authors. Licensee MDPI, Basel, Switzerland. This article is an open access article distributed under the terms and conditions of the Creative Commons Attribution (CC BY) license (http://creativecommons.org/licenses/by/4.0/). 